\title{
Food Safety Traceability Systems in the Maritime Catering Logistics
}

\author{
Basem Azmy Saad Boutros ${ }^{1}$, Mahmoud Mahmoud Hewedi' ${ }^{1}$ Kevin R. Roberts², \\ Farida M. Megahid ${ }^{3}$ \\ ${ }^{1}$ Hotel Studies Department, Faculty of Tourism and Hotels, Fayoum University, Fayoum, Egypt \\ ${ }^{2}$ Department of Hospitality Management and Dietetics, College of Human Ecology, Kansas State University, \\ Manhattan, USA \\ ${ }^{3}$ Hotel Studies Department, Faculty of Tourism and Hotels, Menoufia University, Sadat City, Egypt \\ Email: bas00@fayoum.edu.eg, m m hewedi@yahoo.com, kevrob@k-state.edu, drfaridamm@yahoo.com
}

Received 22 May 2014; revised 28 June 2014; accepted 10 July 2014

Copyright (C) 2014 by authors and Scientific Research Publishing Inc. This work is licensed under the Creative Commons Attribution International License (CC BY). http://creativecommons.org/licenses/by/4.0/

(c) (i) Open Access

\section{Abstract}

This paper aims to explore food safety traceability in the onboard food and beverage operations on cruise ships through a case study approach. Semi-structured interviews were conducted with galley and foodservice staff. Additionally, a self-administered questionnaire was designed and distributed to logistics managers and employees of three Egyptian cruise companies. Results indicated that cruise ships in this study use paper-based and manually-entered (electronically stored) data traceability systems. Managing food safety by effective product recall, complying with legislation, and improving product quality are among the most important perceived benefits identified by foodservice staff. Maintaining a good reputation, ensuring food safety, reducing foodborne illnesses, suppliers' commitment to quality specifications, and maintaining guest confidence are considered the most important benefits from implementing a food traceability system. The results also depicted that the challenges managers face implementing or improving a food traceability system included high cost, absence of unified traceability standards between cruise companies and food suppliers, shortage of skilled staff, and lack of knowledge and satisfaction with current foodservice operation systems onboard cruise ships. Other findings elucidated that the critical success factors for implementing traceability included strict food traceability legislation, ensuring the adequacy and correctness of traceability information, adopting a food traceability system by the cruise company management, the standardization of food traceability information identification, and technology support for food traceability systems implementation from government. Other factors were reported of less importance. This research concluded the urgent need for more cooperation between cruise companies, food suppliers, and relevant governmental authorities to adopt food traceability systems and the need of authorizing and setting compulsory standards and regulations. 


\section{Keywords}

\section{Food Safety Traceability, Cruise Ships, Traceability Systems, Logistics}

\section{Introduction}

\subsection{Cruise Tourism and Related Foodborne Diseases}

In recent years, traveling by sea excursion has become popular. Cruises were first offered through steamship companies from main United States ports, such as New York and Canaveral, as an integrated service which combined sea passage and hotel services [1]. Vogal, Papathanassis, and Wolber [2] indicated that cruising was a fast growing segment of the tourism industry and the innovation in services provided onboard cruise ships had made cruises an attractive vacation option. The package vacations that cruises offer make them one of the most popular tourism products [3] [4]. Véronneau and Roy [5] reported that the cruise industry carried 11.5 million passengers around the world in 2005, and it is estimated to reach 21.7 million by the end of 2014 [6]. Furthermore, North America and Asia have the biggest share of cruise tourism markets [7].

The growth in the cruise industry and the nature of cruise ships as a semi-closed environment in which people live, eat, and drink from common food and water supplies may facilitate the spread of infectious diseases [8]. Mouchtouri et al. [9], stated that features on the ships' water systems, including bunkering from ports, desalination, storage, and proximity to non-potable water systems, could increase the risk rate of contamination. Therefore, cruise ships may be potential sites for disease outbreaks and in particular foodborne and waterborne diseases. Waterman [10] discussed the first well-documented outbreak of Staphylococcal food poisoning onboard a cruise ship. Several studies have reported gastrointestinal outbreaks onboard cruise ships, including E-coli, Norovirus, and Legionnaires' disease, all resulted from food and/or water served onboard cruise ships [11]-[15]. The World Health Organization [7] has noted that many foodborne outbreak incidents on the affected cruise ships are ascribed to cross contamination, use of contaminated raw food, and infected food handlers and indicated that many outbreaks are never informed or told to health authorities and only a small percentage of them are published. Therefore, The United Nations World Tourism Organization [16] indicated that the cruise ship sector required more in-depth studies due to its growth, economic impact, and complexity.

In response to several outbreaks onboard ships, the Vessel Sanitation Program was established by the United States Public Health Service's Center for Disease Control and Prevention in 1975. The goal of the Vessel Sanitation Program was to minimize the potential for gastrointestinal illnesses and it has helped to reduce the rate of diseases outbreaks on ships [5] [8].

\subsection{The Emergence of Food Traceability Concept and Potential Benefits}

Consumers demand a food supply where food safety can be documented and tracked during every stage of production, processing, distribution, and service. Folinas [17], Regattieri [18], and Wu et al. [19] claimed that due to the emergence of Bovine Spongiform Encephalopathy, traceability has become an essential tool for food safety, quality, and tracking within the meat supply chain. Moreover, product quality improvement, need for healthy consumption, reducing risk rate and liability, and brand name protection are among the most common driving forces for traceability system implementation [20]. From a legislative point of view, Engelseth [21] stated that the European Union General Food Law of 2005 required that food and feed business operators identify the immediate supplier of the product in question and the immediate subsequent recipient, which has increased the demand for tractability systems in the foodservice industry.

The foodservice industry has addressed the management of food hygiene, safety, and quality through the introduction of Hazard Analysis and Critical Control Points (HACCP), ISO 9001, and other initiatives. However, Sperber [22] argued that HACCP systemsare not sufficient to ensure food safety in the entire food supply chain when applied alone, it must be supported by prerequisite programs and systems, such as product traceability, feed contamination prevention, and assuring containers and packaging materials safety. Matsuda [23] claimed that food safety procedures alone cannot improve consumer confidence without conveying appropriate information of the product through the implementation of traceability. Many authors have defined the term traceability, 
but most have focused on the same core concept. For instance, The Food Marketing Research and Information Center [24] defines traceability as "the ability to follow the movement of food products or ingredients through specified stages of production, processing, and distribution".

With regard to the application of traceability systems in foodservice, Smith et al. [25] postulated that traceability system would be introduced in the foodservice industry in the near future. Golan et al. [26] noted that some restaurants and grocery stores now require their suppliers to adopt traceability systems, which must be verified by a third-party verification process.

Given that the flowing nature of onboard logistics operation on cruise ships, Véronneau and Roy [5] maintained that sanitation and sourcing of product should be of high importance. Tracking produce and supplies and holding suppliers accountable is critical in ensuring the safety of products onboard. Several recent studies [20] [25] [27]-[30] have contended that there are direct benefits from implementing food traceability systems, including supply chain optimization, enhancing food safety and quality, ensuring product authenticity, complying with food safety legislation, differentiation and competitive business ad-vantages, and responding to specific needs such as consumers with food allergies.

\subsection{Food Traceability Framework and Technical Instruments}

While many models have been introduced to support traceability information systems, each model views the issue from a different perspective. Food traceability systems are based on four elements, product identification and process linking, data to trace, product routing and data retrieval, and traceability tools [3] [18] [31]. The UK Food Standard Agency [27] indicated that products and processes were the key components of a traceability system. Depending on the complexity of the supply chain, the traceability system can be either paper-based or Information Technology (IT) based, which depends on a traceability information carrier that stores and carries related information of a food product. In this concern, optical systems like barcodes, Radio Frequency Identification (RFID), and laser etching on edible labels for fruits and vegetables have been implemented in the food industry [29] [32]-[35].

The majority of literature relating to food traceability focuses on using instruments and potential advantages of adopting a traceability system. There is a paucity of research related to the traceability of food served within a cruise ships' foodservice operations. Therefore, the purpose of this study is to explore food safety traceability systems in the onboard food and beverage operations of passenger' ships. Specific objectives are to:

1. Identify the current traceability status with regard to coordination with food supply companies.

2. Investigate the potential benefits from implementing food safety traceability systems in the onboard logistics.

3. Determine the challenges face implementing food safety traceability systems schemes.

4. Identify the existing success factors for implementing food safety traceability systems.

\section{Methodology}

\subsection{Design of the Case Study}

The case study method was used for this research paper. This method depends on a detailed investigation through data collection from a limited sample to understand the complex relationships that exist. The reason for choosing the case study technique was to obtain a detailed description about the phenomenon under investigation and to understand the features of the case in the real life. According to Finn, Walton, and Elliott-White [36], the case study is based on a combination of data collection methods to improve the validity of the research. Therefore, qualitative and quantitative techniques were adopted in the current study. The data were collected using a self-administered questionnaire that is adopted and developed from previous studies [20] [37] [38]. The questionnaire was prepared, piloted, and distributed to all logistics managers and employees of the investigated cruise ships to produce quantitative data for analysis.

Semi-structured interviews were carried out with galley and foodservice staff onboard cruise ships to identify their views on the potential benefits of implementing an internal food traceability system onboard the ship and the challenges that may affect their implementation of internal food traceability. The interview framework questions are summarized in Figure 1. All interviews were transcribed. An interview lasted, on average, 30 minutes. The study protocol was approved by the universities' institutional review board. 


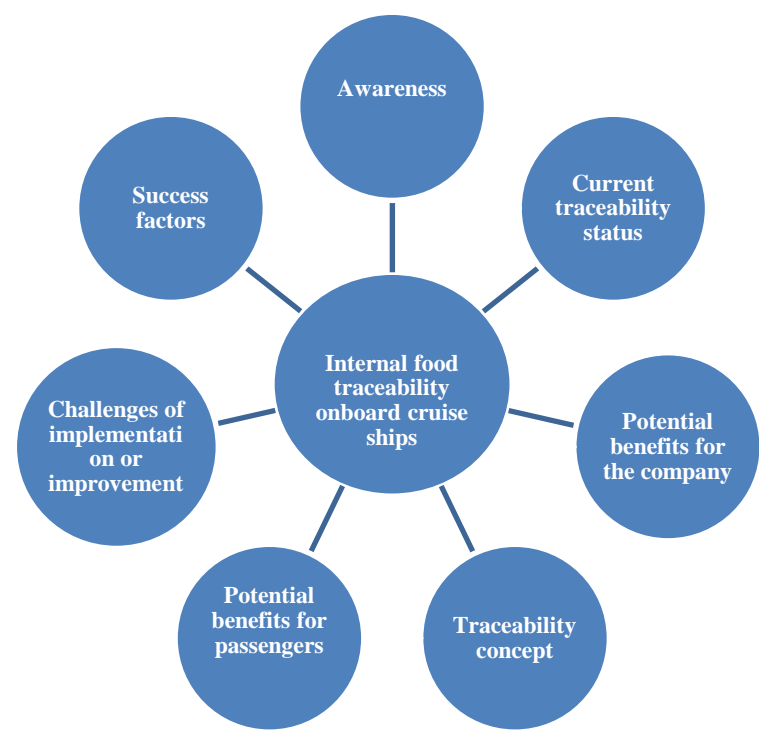

Figure 1. A framework of interview questions.

\subsection{Population of the Study and Response Rate}

The study domain includes three Egyptian cruise line companies that were selected as a convenience sample. The questionnaire was distributed from February to September 2013 to all logistics mangers and staff, only five questionnaires out of 20 distributed was returned. Although the response rate was lower than anticipated, because this study was concerned with developing a thorough understanding of each company's practices and not generalizing the sample to the population, five valid questionnaires were considered sufficient. In addition, three interviews were held with foodservice and galley staff.

\section{Results and Discussion}

\subsection{The Concept of Food Traceability}

All respondents indicated that they know the meaning of the term traceability in the context of the ship's food supply. However, their definitions were limited to the purchasing and storing processes, without dealing with food traceability as it flows through the ship. According to the definitions outlined by the Food Marketing Research and Information Center [24], none of their definitions expressed the proper meaning and purpose of traceability. That may be due to the fact that the concept of traceability is considered new and the attention to food traceability began only few years ago as it was reported by Senneset, Forås, and Fremme [31].

\subsection{Current Traceability Status}

Results from the respondents at the three cruise line companies show that they are currently using a paper-based traceability and manually-entered (electronically stored) data systems. The reason why these companies implement such traceability systems may be because of other advanced electronic systems are costly and not suitable for small businesses as previously found [39]. Other reasons could be lack of knowledge about advanced food traceability systems.

All respondents in the three companies described their traceability system as somewhat satisfactory except one respondent who described it as very satisfactory. Interestingly, all respondents expressed their willingness to change for more advanced traceability systems as a result of explaining to them how this could be beneficiary to their business. Respondents at Company I and Company II want to use bar codes while the respondents at company III would like to change to use a Radio Frequency Identification system (RFID).

\subsection{Potential Benefits of Implementing a Food Traceability System}

The mean scores for the potential benefits of implementing food traceability system are shown in Table 1 . The 
Table 1. Potential benefits of food traceability systems.

\begin{tabular}{ccc}
\hline Potential benefits & Mean & Rank \\
\hline Protecting food safety by effective product recall. & 4.8 & 1 \\
Complying with relevant legislation. & 4.8 & 1 \\
Improving product quality. & 4.8 & 1 \\
Reducing risks associated with food-borne diseases outbreaks. & 4.6 & 2 \\
Differentiating your foodservice operation. & 4.4 & 3 \\
Ensuring food authenticity. & 4.4 & 3 \\
\hline Providing nutrition and allergy information for passengers. & 4.4 & 3
\end{tabular}

three cruise companies investigated deem protecting food safety by effective product recall procedures, complying with legislation, and improving product quality as the most important benefits of traceability. Concerning compliance with legislation, the results agree with what previously stated by Xiong et al. [30] as traceability systems or process could meet each country's food safety legislation and serve the public health. However, the food safety legislation in Egypt does not require a mandatory traceability system and the traceability measures are only addressed to exported food produce through an ongoing project of The Egyptian Traceability Centre for Agro-Industrial Exports. Reducing the risk rate of foodborne disease outbreaks ranked the second potential benefit. Other perceived benefits include ensuring food authenticity, differentiation, providing nutrition and allergy information ranked the third. Reducing production and labor costs ranked the fourth and the fifth respectively as of minor importance. These results agree to some extent with previously reported results [20] [29] [40].

\subsection{The Challenges of Implementing a Food Traceability System}

The results clearly indicated the challenges of implementing a food traceability system include the high initial cost, the absence of unified traceability standards between cruise companies and food suppliers, and the lack of skilled staff and are considered the most important difficulties for adopting a traceability system. Other challenges of minor importance include limited staff time for additional tasks other than their regular formal duties, lack of governmental support, less flexibility in the foodservice operation, no enforcement for recording traceability information, and uncertainty about future benefits. These results are similar to what previously found by Zhang et al. [38].

Chrysochou, Chryssochoidis, and Kehagia [29] indicated that the implementation of advanced traceability systems like Radio Frequency Identification (RFID) is still limited due to the high initial investment. On the one hand, the lack of standardization and the diversity of the traceability systems, resulting in incompatibility between foodservice operations and suppliers in the food supply chain [18] [41] is still a critical issue. On the other hand, the Food Standard Agency [27] has noted that foodservice operations will be apprehensive about investing in a traceability system until they are convinced about its viability. Moreover, Engelseth [21] demonstrated that regulations by governments in terms of demanding food traceability would compel businesses to track food products.

\subsection{Factors of Success for Implementing a Food Traceability System}

The mean scores for the perceived success factors for implementing a food traceability system are shown in Table 2. The mean for nine of the 10 variables were between 3.4 - 4.8; hence, these factors are considered essential for implementing a traceability system. The factor linked to passengers' willingness to pay an increased price for food that is traceable, had a mean value of 2.60. The two highest crucial factors for the success of implementing food traceability system are "Strict food traceability legislation" and "Ensuring the adequacy and correctness of traceability information”. Our findings agree with what was previously reported by Miao [37] as the authenticity of traceability information affects the quality of information and the trust between cruise companies and food suppliers. Moreover, strict laws with regard to traceability are critical, especially in Egypt where traceability is at its early stage and only implemented in food exportation. The factors entitled "senior management requiring a 
Table 2. Success factors for implementing a food traceability system.

\begin{tabular}{clcc}
\hline \multicolumn{1}{c}{ Factors } & Mean & Rank \\
\hline 1. & Strict food traceability legislation. & 4.8 & 1 \\
2. & Ensuring the adequacy and correctness of traceability information. & 4.8 & 1 \\
3. & Senior management requiring a food traceability system. & 4.6 & 2 \\
4. & The standardization of food traceability information identification. & 4.6 & 2 \\
5. & Technology support for food traceability systems implementation from government. & 4.6 & 2 \\
6. & Increased education and training for employees about traceability systems. & 4.4 & 3 \\
7. & Full understanding of food traceability from passengers. & 3.8 & 4 \\
8. & Government funding for food traceability implementation. & 3.6 & 5 \\
9. & Sharing information between the passenger ships and food supply companies. & 3.4 & 6 \\
10. & Passengers' willingness to pay an increased price for traceable food. & 2.6 & 7 \\
\hline
\end{tabular}

food traceability system", "the standardization of traceability information", and "technology support from government" are in the second rank and have the mean of 4.6.

The mean of the factor named "increased education and training for employees about traceability systems" is 4.4 and is 3.8 for that is called "full understanding of food traceability by passengers". This finding agrees with Engelseth [21] who asserted that employees' participation in developing a food traceability system is considered the cornerstone for establishing traceability. Van Rijswijk et al. [42] as well, stated that consumers' perception of food traceability is influenced by conveying other quality assurance information through certified traceable food.

Matsuda [23] stressed on that the role of government in supporting traceability has not just to make laws, but rather providing financial assistance in establishing, developing and promoting traceability procedures. The mean of factor "passengers' willingness to pay an increased price for traceable food" valued only 2, 6 how far is it comparable with similar results. In this respect, Mai et al. [20] reported that bringing traceability and quality assurance together increases the consumer willingness to pay for traceable food.

\subsection{Interview Analysis}

The galley and foodservice staff interviews consisted of seven questions about how they would define food traceability, what internal traceability procedures they were familiar with, what potential benefits they perceived of a traceability system, challenges they face in the implementation of traceability systems and their perceived critical success factors.

Results showed that none of the respondents is aware of the food traceability concept. Ensuring food safety through purchasing and storing processes is the most dominant definition of food traceability represented by the respondents. However, one respondent defined traceability as ensuring appearance quality characteristics of food. Companies subject to the current research use paper based internal system to track food from storerooms to the kitchen. Concerning the potential benefits of implementing traceability; maintaining a good reputation, ensuring food safety, reducing food poisoning and suppliers' commitment to quality specifications were found among the most potential benefits seen by respondents. These results are in good agreement with the previous findings of the questionnaire analysis and Mai et al. [20] and Chrysochou, Chryssochoidis, and Kehagia [29]. Ensuring food safety and maintaining guest confidence were also found as potential benefits for passengers. On the other hand, lack of knowledge, dissatisfaction with the foodservice operation system and high cost onboard of the investigated ships, are respectively the most apparent challenges viewed by interviewee to the implementation of a food traceability system. Apparently, educating and training of employees, management commitment to adopt a food traceability system, and securing financial needs, equipment and technology were found among the most important factors for the success of demanding a traceability system according to the respondents. 


\section{Conclusions}

This paper aims to explore food traceability systems on passenger cruise ships through a case study approach. The focus of a case study is to understand the topic of interest, not to generalize to other populations. Topics explored included identifying the current traceability systems, investigating perceived benefits of implementing food traceability systems, determining if there are challenges to implementing food traceability systems, and identifying the most crucial success factors for implementing food traceability systems in the onboard logistics in cruise ships.

Paper-based traceability systems and manually-entered (electronically stored) data traceability systems were found as the only systems used on the investigated cruise ships. Effective product recall, complying with legislation, and improving product quality were the most important benefits of implementing the traceability. The findings are supported by the previously reported results by previous researchers [20] [29] [30] [40]. The obtained results from the interview showed that maintaining a good reputation, ensuring food safety, reducing food poisoning and suppliers' commitment to quality specifications, and maintaining guest confidence are considered the most important benefits from implementing an internal food traceability system on the cruise ship.

The study also found that the high cost of applications, absence of unified traceability standards between cruise companies and food suppliers, and lack of skilled staff are considered the important difficulties for adopting traceability systems. Interview results indicate that lack of knowledge and satisfaction with current foodservice operation system onboard the investigated ships are the most important challenges for implementing a food traceability system. These findings are supported by research conducted by Zhang et al. [38].

Strict food traceability legislation, ensuring the adequacy and correctness of traceability information, senior management requiring a food traceability system, the standardization of traceability information, and technology support from government were found respectively according to their importance as the most critical success factors for implementing a traceability system onboard cruise ships. According to interview results, educating and training of employees, management's commitment to adopt a food traceability system, and securing financial needs, equipment, and technology were found as the most important factors for implementing an internal food traceability system on the investigated cruise ships.

The findings support the need for more cooperation and interlinking between cruise companies, food suppliers, and relevant governmental authorities to implement food traceability. In addition, the study recommends that more efforts could be put in place by the government to encourage cruise ships to adopt food traceability systems and making them aware of the different systems that could be compatible with them. Future researches are needed to focus on the cost-benefit analysis of using traceability in cruise ships, especially internally. Moreover, the extent to which cruise companies accept and implement traceability systems needs more investigation. Perception and interest of guests related to traceability could be also another subsequent for future research.

\section{References}

[1] Dickinson, B. and Vladimir, A. (2008) Selling the Sea: An Inside Look at the Cruise Industry. 2nd Edition, John Wiley \& Sons, Inc., Hoboken, 68-73.

[2] Vogel, M., Papathanassis, A. and Wolber, B. (2012) The Business and Management of Ocean Cruises. 1st Edition, CAB International, Massachusetts, 3.

[3] Lois, P., Wang, J., Wall, A. and Ruxton, T. (2004) Formal Safety Assessment of Cruise Ships. Tourism Management, 25, 93-109. http://dx.doi.org/10.1016/S0261-5177(03)00066-9

[4] Gibson, P. (2006) Cruise Operations Management. 1st Edition, Butterworth-Heinemann, Massachusetts, 20.

[5] Véronneau, S. and Roy, J. (2009) Global Service Supply Chains: An Empirical Study of Current Practices and Challenges of a Cruise Line Corporation. Tourism Management, 30, 128-139. http://dx.doi.org/10.1016/j.tourman.2008.05.008

[6] Cruise Lines International Association (2014) CLIA 2014 State of the Cruise Industry Report. CLIA, New York, 1. http://www.cruising.org/sites/default/files/pressroom/Infographic.pdf

[7] The World Health Organization (2001) Sanitation on Ships: Compendium of Outbreaks of Foodborne and Waterborne Disease and Legionnaires’ Disease Associated with Ships 1970-2000. http://www.who.int/water_sanitation_health/hygiene/ships/en/shipsancomp.pdf?ua=1

[8] McCarter, Y. (2009) Infectious Disease Outbreaks on Cruise Ships. Clinical Microbiology Newsletter, 31, $161-168$. http://dx.doi.org/10.1016/j.clinmicnews.2009.10.001 
[9] Mouchtouri, V., Bartlett, C., Diskin, A. and Hadjichristodoulou, C. (2012) Water Safety Plan on Cruise Ships: A Promising Tool to Prevent Waterborne Diseases. Science of the Total Environment, 429, 199-205. http://dx.doi.org/10.1016/j.scitotenv.2012.04.018

[10] Waterman, S., Demarcus, T., Wells, J. and Blake, P. (1987) Staphylococcal Food Poisoning on a Cruise Ship. Epidemiology and Infection, 99, 349-353. http://www.ncbi.nlm.nih.gov/pmc/articles/PMC2249300/pdf/epidinfect00005-0124.pdf http://dx.doi.org/10.1017/S0950268800067820

[11] Azara, A., Piana, A., Sotgiu, G., Dettori, M., Deriu, M., Masia, M., Are, B. and Muresu, E. (2006) Prevalence Study of Legionella spp. Contamination in Ferries and Cruise Ships. BMC Public Health, 6, 1-6. http://www.biomedcentral.com/content/pdf/1471-2458-6-100.pdf

[12] Dahl, E. (2006) Norovirus Challenges Aboard Cruise Ships. International Maritime Health, 57, 230-234. http://www.imh.mug.edu.pl/attachment/attachment/5271/R24.pdf

[13] Marucheck, A., Greis, N., Mena, C. and Cai, L. (2007) Product Safety and Security in the Global Supply Chain: Issues, Challenges and Research Opportunities. Journal of Operations Management, 29, 707-720. http://dx.doi.org/10.1016/j.jom.2011.06.007

[14] Said, B., Ijaz, S., Kafatos, G., Booth, L., Thomas, L., Walsh, A., Ramsay, M. and Morgan, D. (2009) Hepatitis E Outbreak on Cruise Ship. Emerging Infectious Diseases, 15, 1738-1744. http://wwwnc.cdc.gov/eid/article/15/11/pdfs/09-1094.pdf http://dx.doi.org/10.3201/eid1511.091094

[15] Weaver, A. (2005) The Mcdonaldization Thesis and Cruise Tourism. Annals of Tourism Research, 32, 346-366.

[16] The World Tourism Organization (2010) Cruise Tourism: Current Situation and Trends. Madrid, UNWTO. http://pub.unwto.org/WebRoot/Store/Shops/Infoshop/4860/F69B/DDF8/6297/2C04/C0A8/0164/E2F3/110111_cruise_ tourism_excerpt.pdf

[17] Folinas, D., Manikas, I. and Manos, B. (2006) Traceability Data Management for Food Chains. British Food Journal, 108, 622-633. http://dx.doi.org/10.1108/00070700610682319

[18] Regattieri, A., Gamberi, M. and Manzini, R. (2007) Traceability of Food Products: General Framework and Experimental Evidence. Journal of Food Engineering, 81, 347-356. http://dx.doi.org/10.1016/j.jfoodeng.2006.10.032

[19] Wu, L., Xu, L. and Gao, J. (2011) The Acceptability of Certified Traceable Food among Chinese Consumers. British Food Journal, 113, 519-534. http://dx.doi.org/10.1108/00070701111123998

[20] Mai, N., Bogason, S., Arason, S., Árnason, S. and Matthiasson, T. (2010) Benefits of Traceability in Fish Supply Chains-Case Studies. British Food Journal, 112, 976-1002. http://dx.doi.org/10.1108/00070701011074354

[21] Engelseth, P. (2009) Food Product Traceability and Supply Network Integration. Journal of Business \& Industrial Marketing, 24, 421-430. http://dx.doi.org/10.1108/08858620910966291

[22] Sperber, W. (2005) HACCP Does Not Work from Farm to Table. Food Control, 16, 511-514. http://dx.doi.org/10.1016/i.foodcont.2003.10.013

[23] Matsuda, T. (2007) Gap as a Baseline, Traceability as a Pipeline to Build Consumer Confidence. Food and Fertilizer Technology Center, 5-15. http://www.agnet.org/library.php?func=view\&id=20110721113951\&type_id=2

[24] The Food Marketing Research and Information Center (FMRIC) (2008) Handbook for Introduction of Food Traceability Systems (Guidelines for Food Traceability). 2nd Edition, FMRIC, Tokyo, 1.

http://www.maff.go.jp/j/syouan/seisaku/trace/pdf/handbook_en.pdf

[25] Smith, G., Tatum, J., Belk, K., Scanga, J., Grandin, T. and Sofos, J. (2005) Traceability from a US Perspective. Meat Science, 71, 174-193. http://dx.doi.org/10.1016/j.meatsci.2005.04.002

[26] Golan, E., Krissoff, B. and Kuchler, F. (2004) Food Traceability: One Ingredient in a Safe and Efficient Food Supply. USDA, Economic Research Services, 2, 19. http://ageconsearch.umn.edu/bitstream/129805/2/featureFoodTraceability.pdf

[27] The Food Standard Agency (FSA) (2002) Traceability in the Food Chain. 19-47. http://multimedia.food.gov.uk/multimedia/pdfs/traceabilityinthefoodchain.pdf

[28] Stringer, M. and Hall, M. (2007) A Generic Model of the Integrated Food Supply Chain to Aid the Investigation of Food Safety Breakdowns. Food Control, 18, 755-765. http://dx.doi.org/10.1016/j.foodcont.2006.01.008

[29] Chrysochou, P., Chryssochoidis, G. and Kehagia, O. (2009) Traceability Information Carriers, the Technology Backgrounds and Consumers’ Perceptions of the Technological Solutions. Appetite, 53, 322-331. http://dx.doi.org/10.1016/j.appet.2009.07.011

[30] Xiong, B., Fu, R., Lin, Z., Luo, Q., Yang, L. and Pan, J. (2010) A Solution on Pork Quality Traceability from Farm to Dinner Table in Tianjin City, China. Agricultural Sciences in China, 9, 147-156. 
http://dx.doi.org/10.1016/S1671-2927(09)60078-X

[31] Senneset, G., Forås, E. and Fremme, K. (2007) Challenges Regarding Implementation of Electronic Chain Traceability. British Food Journal, 109, 805-818. http://dx.doi.org/10.1108/00070700710821340

[32] Sauvage, T. (2003) The Relationship between Technology and Logistics Third-Party Providers. International Journal of Physical Distribution and Logistics Management, 33, 236-253. http://dx.doi.org/10.1108/09600030310471989

[33] Lee, D. and Park, J. (2008) RFID-Based Traceability in the Supply Chain. Industrial Management and Data Systems, 108, 713-725. http://dx.doi.org/10.1108/02635570810883978

[34] Kros, J., Richey, R., Chen, H. and Nadler, S. (2011) Technology Emergence between Mandate and Acceptance: An Exploratory Examination of RFID. International Journal of Physical Distribution and Logistics Management, 41, 697716. http://dx.doi.org/10.1108/09600031111154143

[35] Kück, M. (2006) Chill-On: Ideas and Solutions to Improve Food Quality, Safety and Traceability. http://www.ttz-bremerhaven.de/images/ttzdateien/pdf/publikationen/New-Chill-On-brochure-with-latest-achievments.pdf

[36] Finn, M., Walton, M. and Elliott-White, M. (2000) Tourism and Leisure Research Methods. Pearson Education, Harlow, 81.

[37] Miao, M. (2010) Critical Success Factors for Implementing Traceability Systems in Chinese Food Enterprises. Ph.D. Dissertation, University of Bedfordshire, Bedford, 99-101. http://uobrep.openrepository.com/uobrep/bitstream/10547/135312/1/miao.pdf

[38] Zhang, X., Zhang, J., Liu, F., Fu, Z. and Mu, W. (2010) Strengths and Limitations on the Operating Mechanisms of Traceability System in Agro Food, China. Food Control, 21, 825-829. http://dx.doi.org/10.1016/j.foodcont.2009.10.015

[39] McMeekin, T., Baranyi, J., Bowman, J., Dalgaard, P., Kirk, M., Ross, T., Schmid, S. and Zwietering, M. (2006) Information Systems in Food Safety Management. International Journal of Food Microbiology, 112, 181-194. http://dx.doi.org/10.1016/j.ijfoodmicro.2006.04.048

[40] Poghosyan, A., Gonzalez-Diaz, F. and Bolotova, Y. (2004) Traceability and Assurance Protocols in the Global Food System. International Food and Agribusiness Management Review, 7, 118-26. http://ageconsearch.umn.edu/bitstream/8154/1/0703jo01.pdf

[41] Bechini, A., Cimino, M., Lazzerini, B., Marcelloni, F. and Tomasi, A. (2005) A General Framework for Food Traceability. Proceedings of the Symposium on Applications and the Internet Workshop, Trento, 31 January-4 February 2005. http://www2.ing.unipi.it/ r000099/publications/cimino_pub17.pdf

[42] van Rijswijk, W., Frewer, L.J., Menozzi, D. and Faioli, G. (2008) Consumer Perceptions of Traceability: A Cross-National Comparison of the Associated Benefits. Food Quality and Preference, 19, 452-464. http://dx.doi.org/10.1016/j.foodqual.2008.02.001 
Scientific Research Publishing (SCIRP) is one of the largest Open Access journal publishers. It is currently publishing more than 200 open access, online, peer-reviewed journals covering a wide range of academic disciplines. SCIRP serves the worldwide academic communities and contributes to the progress and application of science with its publication.

Other selected journals from SCIRP are listed as below. Submit your manuscript to us via either submit@scirp.org or Online Submission Portal.
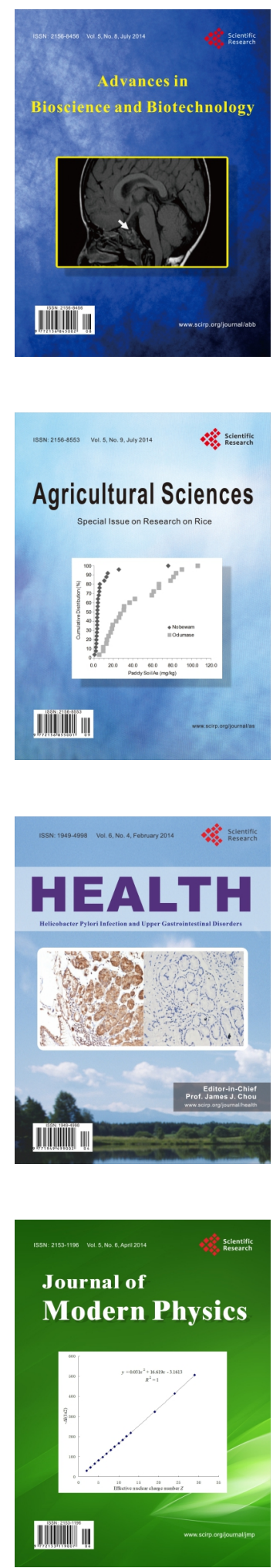
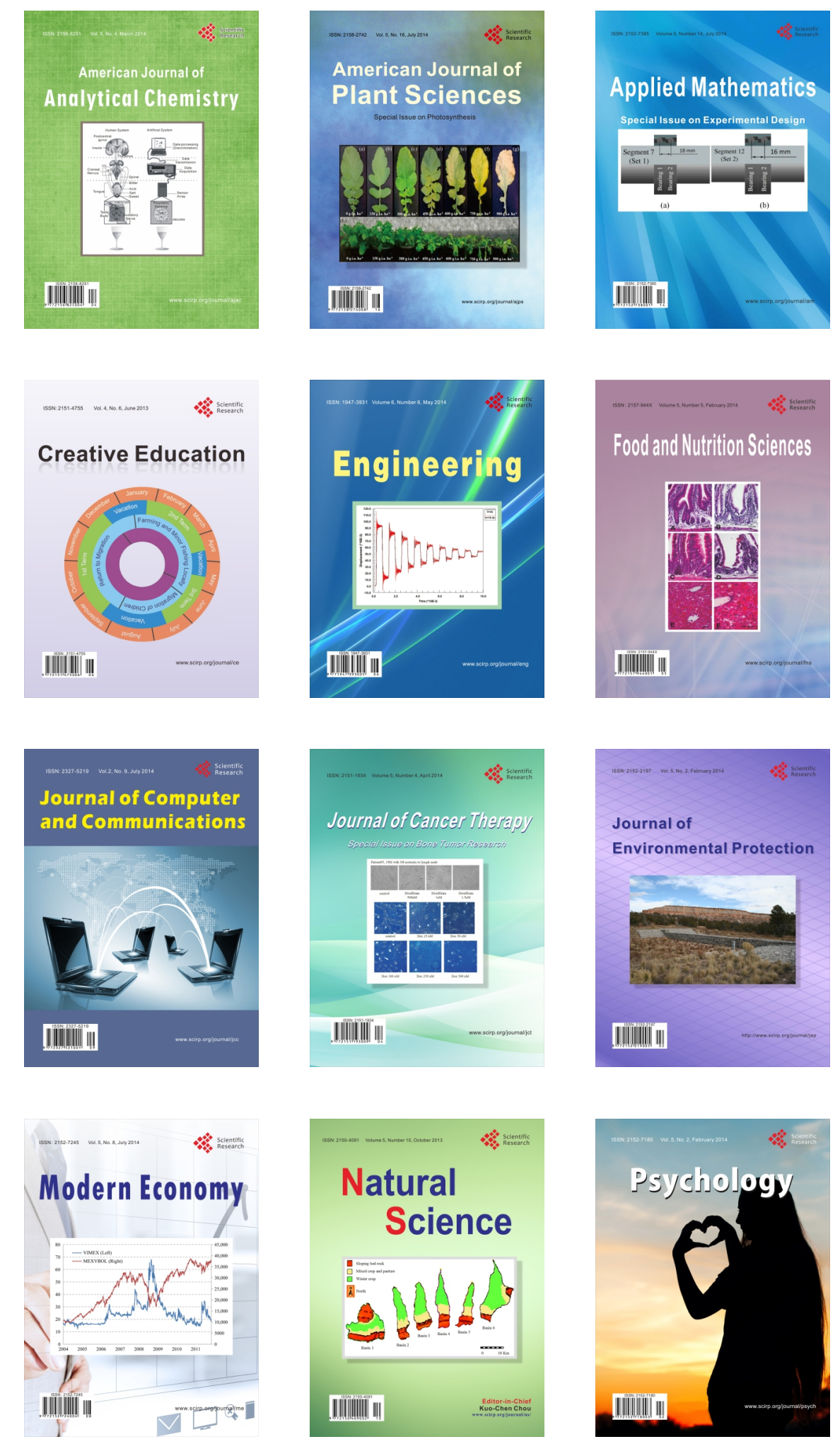